\title{
Héroes, filibusteros y villanos. Representaciones y mitos de la Guerra de Cuba en la prensa gallega del momento (1895-1898)
}

\author{
Teresa PIÑEIRO-OTERO \\ Universidade da Coruña \\ teresa.pineiro@udc.es
}

Recibido: 07/06/2011

Aceptado: 25/07/2011

\section{Resumen}

La Guerra de Independencia cubana de 1895 supuso un hito en la historia de la comunicación al constituir el primer conflicto bélico que traspasó los límites del campo de batalla, y los despachos diplomáticos, para batirse en la prensa.

Cualquier aproximación a esta contienda hace precisa una referencia al papel desarrollado por las principales cabeceras estadounidenses para el fomento de una actitud antiespañolista en la opinión pública de este país. Menos frecuentes son, no obstante, las alusiones a aquellas representaciones y mitos de los que se valieron los periódicos de la Metrópoli para alimentar la superioridad del Imperio español. El presente trabajo ha tenido por objeto analizar las principales imágenes que la prensa gallega del momento vehiculó de ambos bandos de la contienda con una finalidad propagandística.

Palabras clave: Mitos; representaciones; Guerra de Cuba; prensa; opinión pública.

Heroes, filibusters and villains.

Cuban War representations and myths at the contemporary Galician Press

$$
\text { (1895-1898) }
$$

\footnotetext{
Abstract

Cuban Independence War of 1985 was a milestone in Communication History because it was the first one to cross the battlefield and diplomatic offices lines to dueling in Press.

Any approach to this conflict requires references to the role played by major American headers in promoting anti-Spanish attitude. However, there are less references to the representations of metropolis newspapers feeding the illusion of the Spanish army superiority.

The purpose of this study was to examine main images and myths that galician press vehicles on both sides of the conflict.

Key words: Miths; representations; Cuban War; press; public opinion.

\section{Referencia normalizada}

Piñeiro-Otero, T. (2011). Héroes, filibusteros y villanos. Representaciones y mitos de la Guerra de Cuba en la prensa gallega del momento (1895-1898). Historia y Comunicación Social, Vol. 16, páginas 111-130.
}

Sumario: 1. Introducción. 2. Metodología. 3. La guerra de papel. 4. Imágenes del yo y del otro en la prensa gallega. 5. A modo de conclusión. Referencias bibliográficas. Notas. 


\section{Introducción}

Tras el glorioso pasado de España como potencia colonial, el siglo XIX dio comienzo con un Imperio fuertemente mermado y en decadencia. Fue precisamente durante este siglo cuando la Corona española comenzó su transición de imperio a nación mientras luchaba por conservar sus dominios en ultramar y, con éstos, su lugar entre las potencias mundiales (García Mora, 2001).

En 1825, después de la pérdida de las últimas colonias de América continental, del mítico Imperio 'donde nunca se ponía el sol' apenas quedaban Cuba y Puerto Rico en el Caribe, Filipinas y aledaños en Asia, y algunos territorios en el continente africano.

Para hacerse una idea de la situación que atravesaba el Imperio español en este momento resulta ilustrativa la Estadística de las Guerras del siglo XIX de Cernd, capitán del ejército austro-húngaro, que fue reseñada en el Faro de Vigo: "España figura, por desgracia suya, en segundo lugar [después de Turquía] con treinta y un años de guerra (...)" (8 de enero de 1898: 2).

La desvinculación de Cuba de los movimientos sociopolíticos acaecidos en las colonias americanas continentales, que originaron la instauración de estados independientes de la Metrópoli, respondió a los intereses de una burguesía que hipotecó su autonomía política por el mantenimiento de su seguridad económica y prevalencia social (Guerra, 1971; González-Ripoll y García, 1997; Naranjo Orovio, 2009). No obstante, hacia mediados del siglo XIX la situación económica, social y política de la Gran Antilla, causada por la subordinación a la Corona Española, propició el surgimiento de un movimiento nacionalista que generó diversos conflictos bélicos de carácter independentista. El último de ellos fue la Guerra de Independencia Cubana que, epilogada por la Guerra Hispano-Estadounidense, puso fin al dominio español en la Isla y, con éste, a todo un imperio.

Desde la perspectiva de la historia de la comunicación, la popularmente conocida como "Guerra de Cuba" (denominación con la que se hará referencia a las dos guerras concatenadas entre 1895 y 1898 en la Gran Antilla) supuso un hito al constituir el primer conflicto bélico con protagonismo de los medios de comunicación (Wilkerson, 1932; Auxier, 1939; Ruiz Acosta, 1996; Armero, 1998; Companys Monlus, 1998; Leguineche, 1998; o López García, 2001). "Como dentro de una gran campaña militar, para poner a prueba un nuevo tipo de armamento, se desarrolló la batalla en los grandes periódicos de la época" (Sánchez Pupo, 1998: 44).

Hoy por hoy resulta complejo realizar una aproximación a dicha guerra sin hacer referencia al papel que tuvo la prensa estadounidense en la creación de una actitud antiespañolista que favoreció la intervención de los Estados Unidos (en adelante EEUU) en la contienda.

La simpatía que el público norteamericano pudo llegar a tener por los insurrectos cubanos que se enfrentaban a la vieja potencia colonial de los "conquistadores" se vio magnificada por el periodismo de masas de la época y la intervención de los Estados Unidos es difícilmente explicable sin el impulso que recibió de la opinión pública a través de los medios de comunicación (Pizarroso, 1998: 145). 
Con menor frecuencia se trata la responsabilidad de los periódicos españoles en la construcción de una serie de representaciones que alimentaron el espejismo de la superioridad del Imperio español, alentando una guerra por encima de sus posibilidades (Solar, 1998).

Sin embargo, salvo raras excepciones, las principales cabeceras de Madrid así como la mayor parte de las publicaciones periódicas de toda España, mantuvieron una postura de "patrioterismo barato" atendiendo a las doctrinas defendidas por Cánovas del Castillo y Sagasta (Pascual, 1997). El valor mítico del pueblo español se convirtió en el eje del discurso político

No; nosotros tenemos que salir de allí con esplendor y con grandeza; el pueblo que tiene las tradiciones del nuestro, el pueblo que tiene la sangre que el pueblo español y el valor heroico que ahora está demostrando, tiene que venir de América de otra manera; tiene que venir después de una catástrofe gigantesca, si es necesario, o después de una inmensa y definitiva victoria; pero expulsado indignamente, jamás... (Vázquez Mella en Solar, 1998: 239).

Un discurso cuyos principales argumentos provenían del ámbito de los valores simbólicos (identidad, sentimientos, raza, etc.), que impregnó la prensa del momento y permitió mantener vivo el espíritu de 1492 más allá de la suerte de las colonias españolas (Ruiz Acosta, 2001).

Desde las primeras noticias del levantamiento independentista cubano, en febrero de 1898, los periódicos españoles construyeron y difundieron en sus páginas representaciones de ambas caras de la contienda, basándose en la combinación de diversos factores contrapuestos tales como europeo versus criollo, blanco vs. negro o -con posterioridad- hispano vs. estadounidense. Una contraposición en la que los primeros, superiores, suponen la encarnación de los ideales imperiales mientras que los segundos, inferiores, presentan una caracterización negativa.

En este sentido, el objeto del presente trabajo ha sido el de analizar el tipo de representaciones y mitos que la prensa gallega del momento vehiculó de los protagonistas de la Guerra de Cuba de 1898 (españoles, cubanos y norteamericanos) con la intención de conocer la idea que, sobre dicha contienda, imperaba en la opinión pública de la época. Un análisis de las percepciones del "otro" que, siguiendo a Hilton, revela tanto o más del que mira ("yo" o "endogrupo") que del que es mirado ("otro" o "exogrupo") (Hilton, 2010: 16).

\section{Metodología}

Para abordar dicho objeto de estudio, las imágenes que los periódicos gallegos reflejaron de los protagonistas de la contienda, se ha optado por el análisis de contenido como metodología de investigación.

Un análisis cuya muestra conforman las dos principales cabeceras de la prensa gallega del momento, Faro de Vigo (diario decano de la prensa española) y La Voz de Galicia, en el período comprendido entre el 2 de enero de 1895 y el 31 de diciembre de 1898 (años de inicio y de fin del conflicto bélico en Cuba). 
En 1895 el Faro de Vigo (en adelante Faro) y La Voz de Galicia (en adelante La $V o z$ ) eran los periódicos de mayor difusión en Galicia, con una tirada en torno a los 3.000 ejemplares diarios (Barreiro Fernández, 1997). Una difusión que los erigió como principales representantes de las dos corrientes políticas imperantes en la época. Así, mientras $\mathrm{La} \mathrm{Voz}$ representaba la corriente liberal, hasta el punto de que su fundador Juan Fernández Latorre era diputado en las Cortes del Partido Liberal Fusionista por A Coruña, el Faro abanderaba la causa conservadora.

La diferencia de corte político de ambas cabeceras propició una cierta prevalencia del Faro sobre $\mathrm{La}$ Voz en la construcción de imágenes patrióticas exacerbadas para denostar el movimiento autonomista. Una circunstancia que llevó a una aproximación muestral diferente de ambos rotativos. En el Faro se analizaron todos los ejemplares comprendidos entre el 2 de enero de 1895 y el 31 de diciembre de 1898; un total de 1.241 unidades (con los cambios de periodicidad en su publicación ${ }^{1}$ ). En La Voz dicho estudio se limitó a los ejemplares que trataron los acontecimientos más relevantes de la contienda; por ejemplo, el motín de oficiales en la Habana contra diversos periódicos (13 de enero de 1898).

Esta particular perspectiva del Faro sobre "Lo de Cuba" puede relacionarse con la propia concepción de la labor periodística. Mientras $\mathrm{La}$ Voz presentaba una estructura, titulares y contenidos próximos a los de la prensa actual, el Faro continuaba anclado en una organización que disponía la portada para las crónicas de actualidad de carácter no noticioso (como "La Enseñanza experimental", "Electoras y elegidas" o "Las órdenes religiosas y la insurrección") y llevaba a segunda página las noticias propiamente dichas (la mayoría de información sobre Cuba). Unas informaciones cuya estructura y organización -en función de la hora de recepción- remitía a los telegramas que la originaran dando lugar a múltiples contradicciones. Un ejemplo de ello se puede encontrar en el Faro del 28 de abril de 1895, en el que la preocupación por la ausencia de noticias de la Isla precedía a nuevas informaciones sobre la captura de insurgentes por el ejército español.

La diferencia en el modo de abordar la información de ambos periódicos se hizo patente desde las primeras noticias de "bandolerismo" en Cuba, recogidas el 26 de febrero de 1895 (diez días después del Grito de Baire). Así el Faro dedicó a los acontecimientos dos informaciones breves en segunda página ("Las garantías de Cuba" y "El 'Conde de Venadito"'); una de las cuáles incorporaba una crítica a la actuación del Gobierno (en ese momento de corte liberal). Por su parte La Voz pasó esta noticia a portada ("Ecos de Cuba") dedicándole mayor espacio y con una información, recogida de otro periódico de La Habana, que permitía realizar una composición del contexto.

Asimismo, ambos diarios suponían las cabeceras representativas las dos principales ciudades gallegas, Vigo y A Coruña, y sus áreas de influencia. Dos ciudades cuyos puertos adquirieron especial relevancia durante la contienda como punto de partida y llegada de los barcos de $\mathrm{Cuba}^{2}$. Las noticias del movimiento de tropas en el puerto tuvieron eco en la prensa local, como también la convalecencia de los heridos de guerra "Desembarco de tropas en La Coruña. Heridos y enfermos" (Faro, 2 de enero de1896). 
En definitiva, el análisis de ambos diarios ha permitido realizar una aproximación a las representaciones y mitos existentes en sus páginas y, por ende, a la opinión pública gallega como muestra de la española (ambas entendidas como la opinión de la clase social, económica y política imperante). Aproximación que fue complementada con otro tipo de fuentes bibliográficas relativas al contexto histórico o al papel de la prensa en la contienda (particularmente al de la estadounidense), así como con los datos aportados por investigaciones previas sobre el tratamiento del conflicto cubano en los periódicos españoles (nacionales y locales).

\section{La guerra de papel}

La insurrección independentista cubana contra el dominio español, iniciada el 16 de febrero de 1895, brindó a la prensa la primera oportunidad de estas características para mostrar su poder de influencia en la opinión pública. "Nunca antes el papel político de la prensa estuvo a tal altura" (Sánchez Pupo, 1998: 44).

Además de la prensa española y cubana, los intereses estadounidenses en el Caribe favorecieron que los periódicos de este país ofreciesen una cobertura completa de los acontecimientos. De este modo, pese al papel desarrollado por la Associated Press en la información de la contienda, fueron diversos los rotativos que contaron con sus propios reporteros en la Isla (Wilkerson, 1932; Pizarroso Quintero, 1998). El World y el Journal enviaron a sus mejores corresponsales a Cuba y otros periódicos como el Sun y el Herald dispusieron de enviados especiales (Wilkerson, 1932: 6).

El particular tratamiento que la prensa de EEUU dio a determinados sucesos acontecidos en la Gran Antilla propició la formación de una imagen negativa de los españoles y de su política colonial en el Caribe. Imagen que alimentó los estereotipos sobre el pueblo español presentes en el discurso público norteamericano a lo largo del s. XIX (Castillo en Hilton, 2010). De hecho, como subraya Arroyo Cabello (1998:15), los periódicos contribuyeron a la creación de un ambiente antiespañolista ya existente en las altas esferas dirigentes.

La influencia de la prensa estadounidense se fundamentó en la existencia de un gran público lector interesado por la actualidad y el debate político (López García, 2001: 807). Un público a quien las cabeceras norteamericanas pretendían atraer con los titulares y reportajes más estremecedores.

Los abanderados de este momento fueron The New York Journal, de William Randolph Hearst, y The New York World, de Joseph Pulitzer; periódicos cuyas crónicas "aireaban todas las atrocidades de aquella guerra, sobre todo si perjudicaban a España" (Solar, 1998: 244). Este marcado posicionamiento resultaba rentable en términos políticos, una opinión pública favorable a la intervención en Cuba, y económicos. En 1897, un año después de iniciada la guerra en la isla española, los periódicos de Pulitzer y Hearst tenían una difusión superior a los 800.000 y 700.000 ejemplares diarios, respectivamente, llegando a triplicar la tirada conjunta del Tribune, Post y Times, contrarios a la contienda (Thomas, 1973). 
Esta expansión de los principales rotativos estadounidenses permitió una difusión única de los acontecimientos en Cuba, que eran convertidos en atrocidades cuando tenían como protagonistas a las fuerzas españolas.

La bárbara guerra que ambos bandos practicaban era acentuada más aún por la prensa norteamericana, como sucedía con aquellas crónicas del corresponsal de New York World, Silvester Scobel, capaz de escribir, por ejemplo, que los soldados espanoles cortaban, habitualmente, las orejas de los cubanos muertos en combate, para lucirías como trofeos. Para esos periódicos, Weyler era la hiena mallorquina, el tigre de la manigua o el carnicero (Solar, 1998: 244).

Al igual que sucedía en EEUU, la prensa española trató de influir en la opinión pública respecto de los acontecimientos devenidos en la Gran Antilla. Un papel que se hizo especialmente patente en la construcción del enemigo yankee, cuya intervención en el conflicto permitió transferirle la responsabilidad de la situación, desviándola de los verdaderos problemas de carácter interno (Elorza en Sevilla Soler, 1998: 279).

En sus páginas los periódicos españoles vehicularon el posicionamiento de distintos grupos políticos y económicos ante la problemática colonial, y ante la intervención estadounidense en el conflicto (Sevilla Soler, 1998). No obstante, el papel asumido por la prensa española en la conformación de un estado de opinión se desarrolló en un contexto que difería bastante del estadounidense.

A finales del s. XIX España era un país atrasado, con alta tasa de analfabetismo, que contaba con múltiples cabeceras de escasa difusión concentradas en las grandes ciudades. Referirse a la opinión pública española suponía hacerlo de "reducidos públicos burgueses de las grandes ciudades (muy particularmente de la capital), cuyo pequeño número no les impedía monopolizar [la], a ojos de los políticos" (Calvo Pérez, 2001: 807). Pese a ello, Rubio señala que la sociedad española de la Restauración destacaba en Europa por su politización y apasionada lectura de la prensa (en Iglesias Eirís, 2008:17).

En este contexto, los rotativos españoles ofrecieron una imagen distorsionada de los ejércitos de ambos bandos, potenciando el valor de los contendientes patrios como elemento de identidad española.

Bajo una lluvia de plomo nos lanzamos al momento a las trincheras enemigas animados por nuestros jefes y oficiales que gritando ¡Viva España! ¡Viva Murcia! fueron los primeros en llegar al sitio donde el enemigo estaba guarecido (...) (Faro, 2 de enero de 1898)

En la narración de los hechos noticiosos la prensa combinaba la realidad del suceso con un sinfin de representaciones y mitos con los que justificaba la superioridad de la "raza hispánica" respecto de los impíos americanos; unas páginas en las que se criticó hasta la saciedad el "materialismo yankee" frente a la "espiritualidad católica" española (Calvo Pérez, 2001: 808). Este discurso plagaba las páginas de 
unos rotativos en transición del "periódico evangelizador" a la prensa del "factory system” (Seoane y Sáiz, 1996).

Todo lo relacionado con la Guerra de Cuba, como la imagen de los EEUU en España, estuvo determinado por la intervención mediática en aquel conflicto.

La acción política está pidiendo a todos circunspección y prudencia, está exigiendo que las fuerzas de los elementos políticos -y ninguno hay que pueda desarrollarlas tan poderosas como la prensa- vayan encaminadas, no a fustigar a los propios sino a atraer a los extraños (sic) (...) ( La Voz, 14 de enero de 1898).

Los periódicos sobrepasaron las cifras de ventas previas a la contienda y su difusión se multiplicó con la transmisión oral de sus informaciones. Gracias al sistema de reclutamiento, que afectó a las clases más humildes, el interés por la guerra se extendió a todos los estratos sociales y la prensa se convirtió en el único contacto con la "realidad" de ultramar (Sevilla Soler, 1998: 269).

La construcción del conflicto bélico y de sus principales protagonistas, en las páginas de los diarios, logró permear la opinión pública, consolidando a la prensa como un verdadero ejército con una campaña bélica cuidadosamente orquestada. Las mayores ofensivas y contraofensivas no se dieron en los frentes implicados sino en las páginas de los múltiples rotativos que cubrieron la contienda.

En la prensa gallega solían incluirse informaciones recogidas de periódicos estadounidenses sobre la cuestión de Cuba, siempre alertando de su escasa credibilidad con expresiones del tipo de: "por conducto sospechoso", "rumores que no se confirman", "sin fundamento", "por elementos que nos son hostiles" o un "canard jingoista".

Respecto a los telegramas del New York Herald basta, para reconocer que todos son un hatajo (sic) de falsedades, saber que el corresponsal de dicho periódico en la jurisdicción de Santiago de Cuba es nada menos que el cabecilla filibustero Amador Guerra, el cual (...) recomienda al diario yankee, desde su campamento de Manzanillo, que no crea en ninguna de las noticias que acerca de derrotas de los insurrectos publica el Gobierno español. ( $\mathrm{La} \mathrm{Voz}, 14$ de abril de 1895)

El paradigma del poder de la prensa en esta guerra fue el telegrama que Hearst envió a uno de sus corresponsales en la Isla, el dibujante Frederic Remington, cuando en la primavera de 1897 propuso su regreso ante la ausencia de hechos noticiosos: "Permanezca en la Habana. Vd. pone las imágenes, yo pongo la guerra" (Pizarroso Quintero, 1998:146). Una respuesta que reflejó el posicionamiento del Journal en el conflicto cubano, reportándole el sobrenombre de "Mr. Hearst's War" (Cambell, 2001:2).

Este poder de la prensa también se hizo patente en la credibilidad que la clase política española dio a algunas de las informaciones difundidas en los rotativos de EEUU. El propio Canalejas aceptó como válidas las cifras de fallecidos que, sobre el programa de reconcentración de Weyler, publicaron los diarios estadounidenses: una tercera parte de la población cubana (Companys, 1998). 


\section{Imágenes del yo y del otro en la prensa gallega}

La delicada situación que atravesaba España en los últimos años del siglo XIX, apenas una sombra de la gran potencia colonial de antaño, llevó al corresponsal de The Times en la Habana a cuestionar la idoneidad de mantener una guerra tan costosa: "es hora de que el país reconsidere que va abocado a un suicidio moral. Y, contra esa desangrada España se permite luchar la opulenta nación norteamericana, además de ultrajarla y humillarla de todas las formas imaginables" (Maestro, 1998: 95-96).

Sin embargo, la retirada de la guerra de Cuba y la consecuente pérdida del control de la Gran Antilla no suponía una opción posible para la opinión pública española (la élite económica y social) ni para la clase dirigente.

(...) es necedad manifiesta pensar, que después de tanto sacrificio y logrado que sea el éxito, España puede contradecirse abiertamente y mostrarse pusilánime en la victoria, renunciando a sus frutos, habiéndose mostrado tan fuerte y tan constante en la pelea. (Faro, 15 de noviembre de 1896)

La prensa alentó la participación de España en la contienda basándose en representaciones míticas de la cultura, sentimientos y raza española, así como en su deber de hacer frente a un enemigo estereotipado negativamente. Unas representaciones que el discurso periodístico construyó por contraposición de aquellos elementos característicos del endogrupo (españoles e inclusive gallegos) y del exogrupo (independentistas cubanos o yankees).

Esta caracterización dialéctica del ejército patrio y de sus enemigos en Cuba, reflejada en los rotativos españoles, fue completada con una serie de mitos arraigados en el discurso españolista de la época como

Numancia, Sagunto, Covadonga, Las Navas, San Quintín, Lepanto, Zaragoza, Bailén o Arapiles son reivindicados como muestras de un aguerrido carácter español que se conserva intacto. Y esto sucede incluso a nivel específicamente gallego (...) con reivindicaciones del bravo carácter galaico, que se demostró en épicos episodios como el del Monte Medulio o la lucha contra los franceses en Ponte Sampaio (Iglesias Amorín, 2008: 25).

Las noticias que el Faro y $\mathrm{La}$ Voz difundieron de ambos bandos y de sus protagonistas, estereotipados en función de su grupo de pertenencia, han permitido extraer una serie de imágenes que polarizaron el discurso de la prensa gallega sobre la Guerra de Cuba. Imágenes que han sido confrontadas con diversas fuentes bibliográficas en busca de conocer el núcleo de verdad (kernel of truth) sobre el que se sustentaron.

\subsection{EI heróico ejército}

La representación de la propaganda bélica por antonomasia es la del héroe como personificación de aquellos valores -casi míticos- que conforman una determinada 
identidad nacional. "Del héroe anónimo, del soldado no hay para que hablar: es español y con eso basta. Pero de los catalanes y gallegos que forman en su inmensa mayoría el batallón de Murcia, se puede decir, con razón, que son de hierro (...)" (Faro, 30 de diciembre de 1897).

Durante la Guerra de Cuba este ideal patrio fue representado por el ejército español, bien como un heroísmo individual, como en el caso del "bravo sargento D. Alejandro Salgado natural de la provincia de Orense" (Faro, 2 de enero de 1898), o colectivo: "La infantería se portó con bizarría, siendo admirablemente secundada por la artillería que, con sus certeros disparos, causó grandes destrozos en el campo enemigo" (Faro, 31 de marzo de 1897).

La prensa gallega se refería al ejército como "nuestros valientes soldados" al tiempo que se hacía eco de sucesos que servían para refrendar cualidades como coraje, fuerza, heroicidad, bravura, astucia o pericia. "Allí la lucha fue cuerpo a cuerpo; peleaban uno contra cinco y en esta desigual refriega cayó herido el sargento, sin cesar por eso de estimular y alentar con energía, a los suyos hasta que llegó el resto de la fuerza" (Faro, 2 de enero de 1898).

Además de dichos atributos los periódicos solían construir relatos en los que se ponía de manifiesto el orgullo, humanidad o el honor del soldado español; cualidades que lo hacían digno merecedor de dicho nombre. Un ejemplo es la actuación del general Hernández Velasco en la captura del cabecilla insurrecto Rius Rivera.

Cuando el general Velasco vio al cabecilla Rius Rivera tendido en tierra en el mal estado que le dejaron las heridas que recibió, tendiéndole una mano le dijo: siento, como hombre, lo que a usted le sucede, a lo que el cabecilla contestó diciendo: ¡qué quiere usted! azares de la guerra. Hónrome, sin embargo, en medio de mi desgracia con poder estrechar la mano del general y caballero que tan digno proceder observa conmigo (Faro, 2 de enero de 1898).

Mientras en la prensa española imperaba un clima de optimismo sustentado en la superioridad y heroicidad del ejército patrio, la proximidad de los rotativos gallegos a los principales puertos de aprovisionamiento bélico favoreció la filtración de noticias referidas a la decadencia moral y física de los retornados de Cuba.

De hecho, la realidad del ejército español difería de su representación periodística. A finales del siglo XIX la capacidad militar española se había visto reducida -de forma importante- por las guerras internas y externas (que propiciaron la pérdida de su potencia colonial) y los levantamientos acaecidos en Cuba y Filipinas. En este contexto la Corona española continuó manteniendo guerras a miles de kilómetros de distancia y destinando a ellas reemplazos "cada vez más numerosos y peor adiestrados de mozos que, en su mayoría, iban a aquella guerra contra su voluntad y casi resignados a la muerte porque carecían de las 1.500 pesetas necesarias para pagar su redención en metálico" (Solar, 1998: 239).

La dificultad para el reemplazo del ejército de Cuba fue reflejada en la prensa gallega del momento, entre representaciones míticas del valor español y de la gloria de sus soldados. El llamamiento de 20.000 hombres en los primeros meses del conflicto generó un debate sobre la prevalencia de reservistas militares o de exce- 
dentes de cupo para dichos puestos. El Faro llegó a crear una sección que, bajo el título de "Llamamiento de 20.000 hombres", recogía toda la información relativa a dicha cuestión.

El ejército español de la Gran Antilla, en cuya gloria se había asentado la identidad nacional e imperial en las páginas de los diarios patrios, distaba bastante de ser tan heroico y valeroso. Pese a que en vísperas de la guerra la Corona española contaba con el mayor ejército reunido en América, 216.000 efectivos más otros 120.000 entre voluntarios cubanos y guarniciones de Puerto Rico y Filipinas, éste no se correspondía con una fuerza militar real. La escasa formación y valor militar, sumados a las numerosas bajas y a las necesidades humanas de las guarniciones fijas, limitaban dichos efectivos a una tercera parte (Solar, 1898: 252).

Además, la dificultad del reclutamiento de "voluntarios" llevó al Gobierno a conceder la amnistía a los desertores del ejército que quisieran "redimirse" por la patria. En abril de 1895 la prensa gallega se hizo eco de la resolución del Ministro de la Guerra de indultar a los prófugos del Ejército, “(...) a condición de que pasen a prestar servicios en el Ejército de Cuba" (Faro, 18 de abril de 1895).

En lo que respecta a la flota española, insuficiente para mantener el dominio colonial en ultramar (Solar, 1998), los rotativos gallegos continuaron ofreciendo una imagen de potencia naval al tiempo que despreciaban las dotaciones estadounidenses $^{3}$. Una representación a la que ayudaron hazañas bélicas como la del contralmirante Cervera, quien en la primavera de 1898 tuvo en vilo a los EEUU por su habilidad para despistar la escuadra yankee.

\subsection{La "buena" Metrópoli y la colonia necesitada}

Otra de las ideas más frecuentes en la prensa gallega del momento fue la necesidad de tutela de las colonias por la Metrópoli, así como una defensa a ultranza del modelo colonial del imperio español. Un modelo cuya idoneidad no era compartida por los cubanos y que derivó en un sentimiento antiespañolista inculcado desde niños.

Ahí tenemos -dice- dándose en las escuelas como trozos de lectura los libros de Mantilla y de Guiteras (...) y trozos selectos de autores hispano-americanos, o mejor aún, de hispanófobos. En estos trozos se destroza a España, se critica su colonización y se hace la apología de la independencia de los pueblos de América que pertenecieron a su corona (Faro, 24 de marzo de 1897).

Si bien Metrópoli y colonia diferían en su visión sobre la política colonial en la Isla, la condición de Cuba como provincia española resultaba indiscutible. Una condición que tuvo un importante calado en la opinión pública, hasta el punto de que políticos como Cánovas se posicionaron tajantemente contra cualquier maniobra autonomista en la Isla dado su carácter de "regular provincia, que no puede gobernarse a sí misma" (Solar, 1998: 241).

Por esta razón España contestó al Grito de Baire con "a millares los hombres, a torrentes el dinero: oro y sangre con prodigalidad tal que ninguna nación podría 
igualar a la nuestra en el esfuerzo" ( $L a \mathrm{Voz}, 25$ de enero de 1896).

La obligación con una colonia superaba, atendiendo al discurso imperante, cualquier limitación posible y justificaba -para la prensa gallega- el sostenimiento de una guerra por encima de las posibilidades españolas. No se trataba ya de los beneficios económicos que a la Corona reportaban los ingenios de azúcar insulares, ni tampoco la posición estratégica de la Gran Antilla; los periódicos hablaban de orgullo, honor o de responsabilidad como Metrópoli.

Los esfuerzos supremos que la nación ha realizado para sostener el honor de España en la isla de Cuba -que no otra cosa trata allí de sostenerse, porque no es aquella una colonia productiva para nuestro país -han superado a cuando han hecho otras naciones en caso análogo; y no podemos menos de reconocer que esos esfuerzos sólo respondieron a los nobles impulsos de patriotismo que todos sintieron, desde el Gobierno hasta el último ciudadano, ante la infame rebelión que, sin fundamento alguno, se levantó en aquel territorio (...)

Tal vez si se hubiera pensado con la fría calma de los ingleses en estos actos espontáneos (sic) que se han realizado, hubiéramos comprendido que la nación iba más allá de lo que, dados sus elementos, debiera ir, porque no es lógico en manera alguna que un país empobrecido por muchas causas y entre ellas principalmente por el estado de abandono en que se halla su agricultura, vacíe la caja de sus caudales y se desprenda de la lozana juventud que debe dedicarse a las faenas agrícolas para sostener una contienda, que en realidad, debió confiarse a los esfuerzos del país sublevado (Faro, 13 de marzo de1897).

Para la prensa, sin embargo, esta obligación de la Metrópoli no debía hacer vacilar la política de guerra contra el autonomismo "prescindiendo de toda clase de sentimentalismo e idealismo de la tutela colonial" (Faro, 30 de junio de 1895).

El mito sobre la imposibilidad de Cuba de autogestionarse se continuó alimentando en los periódicos gallegos, inclusive tras el establecimiento del Gobierno Autónomo. Una circunstancia que propició algunas referencias al "arriesgado ensayo que está haciendo de la autonomía" (Faro, 8 de enero de 1898) especialmente desde el Faro.

\subsection{Filibusteros y bandoleros}

Las primeras noticias que la prensa gallega recogió de la insurrección cubana no se referían a ésta como un movimiento de carácter independentista, sino que lo deslegitimaron tratándolo de bandolerismo - a veces separatista- o bandidaje. Las principales cabeceras se refirieron a la actuación española para "estirpar el bandolerismo y separatismo" o a "la persecución del bandidaje", como refleja esta información publicada en el Faro (28 de febrero de 1895) acerca de la confrontación de miembros del ejército y una partida de bandoleros: “(...) ocurrió un pequeño encuentro entre una partida de malhechores y algunas fuerzas del Ejército (...) En aquella zona apareció otra partida separatista al mando de Manuel García, la cual se dedica al pillaje y al robo". 
Las alusiones a los insurrectos cubanos en estos términos, como bandoleros o vulgares malhechores, sintetizados en la denominación de "filibusteros" (piratas que en el S.XVII infestaron el mar de las Antillas) estuvieron presentes -prácticamenteen todas las informaciones del conflicto en los rotativos analizados.

El término filibusteros fue incorporado al vocabulario habitual sobre la contienda cubana, también por la prensa extranjera, con una intención claramente deslegitimadora. El Faro del 30 de diciembre de 1897 describía una viñeta humorística publicada en el New York Herald cuya representación de los insurgentes era acompañada por el texto "Aquí no se admiten piratas".

De este modo la prensa gallega se hizo eco de la existencia de un nexo de unión entre el movimiento independentista y el bandolerismo cubano, que potenció y amplificó negativamente con fines propagandísticos.

En efecto, como pusieron de relevancia diversos trabajos a partir de la década de los 80, el bandolerismo cubano del s. XIX suponía un modo de protesta social vinculado a las transformaciones en el rural. Balboa (citado en Santamarina y Naranjo, 2008) coincide con otros autores al señalar que diversas partidas de bandidos se unieron a los insurrectos cubanos, quienes se valieron de su experiencia combativa y conocimiento del terreno.

La representación de estos piratas y bandoleros en los periódicos gallegos no pudo ser más negativa. Los insurrectos eran representados como diabólicos, crueles, miserables, ladrones, asesinos, forajidos, impíos, bárbaros, etc. Una caracterización a menudo implícita en los estremecedores relatos de las actuaciones filibusteras

Los detalles que se conocen sobre el ataque y toma de Guisa por las fuerzas de Calixto García, son horrorosos; resístese la mente a creerlos; tanta es la crueldad y el salvajismo que los ha animado. (...) En los alrededores, se veían cadáveres de niños y mujeres, que se conoce fueron cazados a tiros al pretender huir. Una mujer se encontró con cuatro machetazos en el cuerpo (...) Se encontraron muchos cuerpos carbonizados de hombres amarrados a los postes con alambres, otros ligados a las camas y taburetes, lo que demuestra que la crueldad y las venganzas han sido llevadas a cabo con toda premeditación y refinamiento (Faro, 4 de enero de 1898).

Los insurrectos cubanos eran definidos en las páginas de los periódicos como crueles salvajes pero cobardes, diestros en los ataques a la población civil pero incapaces de resistir los embates del ejército español, ante el cuál abandonaban la lucha. Con relativa frecuencia el Faro incorporó noticias de insurgentes que se entregaron a los mandos españoles afirmando la existencia de coacciones para participar en la revolución de la que desertaban.

Han llegado a esta corte los cabecillas Ibáñez y Aranjo, que capitaneaban en la isla de Cuba una partida de cien hombres en la provincia de Villas y que se dispersó voluntariamente (Faro, 4 de abril de 1895).

Se han presentado a las autoridades el titulado teniente Dámaso Fernández y 9 de los suyos, los cuales han manifestado que hace tiempo deseaban retirarse de la insurrección, pero que hasta ahora nunca les había sido posible realizarlo por la gran vigilancia que sobre ellos se ejercía (Faro, 31 de marzo de 1897). 
En ocasiones el Faro y $\mathrm{La}$ Voz mostraron excepciones a la representación diabólica de los insurgentes. Ejemplo de ello fue la captura del general rebelde Flor Crombet, cuya condición de inteligente e instruido contrastó con la imagen del bandolero analfabeto difundida por la prensa, o la descripción de Manuel García "El Rey" que recogió el Faro del rotativo antillano La Lucha con motivo de su deceso (1 de marzo de 1895):

(...) Quién va a resistir las decisiones supremas del Rey, alto, musculoso, ágil, trigüeño, rosado, exuberante de vida, arrogante figura, expresión simpática, inteligente y cortés y que por su porte y cara revela, desde luego, una extraordinaria superioridad sobre los demás?

Se trata de excepciones en una caracterización extremadamente negativa en la cual, como se verá a continuación, el componente racial se hizo especialmente importante.

\subsection{Los cabecillas mambises}

Hacia finales del s. XIX en Cuba existía una mayoría de habitantes pertenecientes a la raza negra, derivada de la esclavitud en la isla, a los que se sumaba la incipiente comunidad de inmigrantes orientales trabajadores en la industria azucarera. Una superioridad numérica que no se traducía en términos de dominio, asumiendo la raza blanca el poder, el ejército y la marina, además de todas la plazas y fortalezas de la isla (Saco, 1948).

Si el honor de la raza española supuso un leitmotiv en el discurso político y periodístico de la Metrópoli, ésta también focalizó el argumentario de los autonomistas cubanos. En Ideas sobre la incorporación de Cuba en los Estados Unidos, Saco manifestó su preocupación -común a las la élites cubanas- de que su odio hacia la Metrópoli repercutiese favorablemente en una revolución social y, con ésta, en "la ruina completa de la raza cubana" (Saco, 1948: 3). Una ruptura del orden establecido que dio lugar a un temor mayor; a "que algún día pudiera disiparse la divisoria estática entre dos tipos naturalmente diferentes de individuos (...)" (Hernández Sandioca, 1998: 8).

Tras el inicio de los alzamientos independentistas en la Gran Antilla, durante la segunda mitad del s. XIX, el ideal nacional reformista blanco dio paso a considerar como cubano a todo aquel que estuviese dispuesto a luchar por la independencia de la Isla, fuese cual fuese el color de su piel (García Moral, 2001).

La bandera de la autonomía (...) es una bandera más traidora, más peligrosa, más perniciosa, más rebelde que la bandera misma del filibusterismo, más franca y que sin soslayos lleva a la manigua con bandidos que se juegan el pellejo, sus pretensiones negras y mulatas (Faro, 30 de junio de 1895). 
Además de la población negra, en 1895, existía en Cuba otro colectivo "naturalmente privado de sus derechos": los chinos. Colectivo que había llegado a la Isla como mano de obra para los ingenios azucareros en sustitución de la esclavitud africana.

Al igual que los negros mambises, los chinos habían visto en la insurrección cubana la posibilidad de dignificarse y adquirir los derechos que les eran negados. Una esperanza que ya les había llevado a combatir en la Guerra de los Diez Años.

Cuando las fuerzas cubanas obtuvieron el levantamiento en armas de los braceros de caña, los oficiales chinos explicaban a sus paisanos las razones de la guerra y llenos de entusiasmo juraban servir la bandera de la República. Los años de servidumbre enervante, no habían logrado destruir las fibras de nobleza en sus almas. Peleaban contra la bandera que los había esclavizado; eran compañeros en la necesidad de aquellos que como ellos habían sufrido el yugo colonial (De Quesada, 1868: 7).

Los hombres de ambas razas, africana y oriental, fueron integrados en el Ejército Libertador de Cuba llegando a liderar algunos destacamentos por méritos de guerra. En este contexto, la prensa gallega adoptó la costumbre de referirse a los líderes insurgentes por su grupo racial de pertenencia, siempre que éste no fuese el "imperante". Expresiones como "El negro Guillermo Mendoza, conocido por Guillermón", "el cabecilla Carillo y el negro González" o "el chino viejo" eran frecuentes para redundar en el origen salvaje de estos cabecillas que, como el líder militar Maceo (mulato), suponían la encarnación del odio secular hacia la raza blanca. En el caso del negro Guillermón, "uno de los más terribles cabecillas separatistas" este odio fue refrendado por su calidad de dirigente de "una banda de negros rebeldes" (Faro, 13 de marzo de 1895).

Del mismo modo sucedía con aquellos líderes no-cubanos de la insurrección que, como Máximo Gómez "cabecilla dominicano", el "ruso Roloff" o los cabecillas yankees, eran citados por la prensa junto a su origen para subrayar su carácter foráneo y -con éste- su rencor hacia España. Inclusive en casos como el de Flor Crombet, "de todos los jefes blancos de los separatistas, el más distinguido por inteligente y bravo" capaz de "contener a los negros y mulatos", el origen francés de su familia fue utilizado por las cabeceras gallegas para explicar su carácter antiespañolista. Una condición de extranjero que la prensa no pudo justificar para José Martí, cuyo liderazgo de la insurrección fue tildado de parricidio en las páginas de los periódicos.

\subsection{Los Yankees}

$\mathrm{Si}$ al inicio del alzamiento el papel de enemigo era atribuido de un modo claro y explícito a los insurgentes cubanos, ya fuesen bárbaros filibusteros o negros salvajes, a medida que avanzaba la contienda se fue perfilando el "verdadero" enemigo: EEUU. Un papel que la prensa gallega les adjudicó gradualmente, con el desarrollo del conflicto en la Gran Antilla, y que acabaron por monopolizar tras la "provocación" -como le llamaron los periódicos gallegos- del Maine (24 de abril de 1898). 
Esta progresiva identificación de los EEUU con el enemigo se puede observar en los ejemplos siguientes:

El representante de los Estados Unidos aseguró al Sr. Sagasta en nombre del Gobierno de Washington que vigila a los separatistas cubanos y está dispuesto a impedir que conspiren y embarquen pertrechos de guerra (Faro, 5 de marzo de 1895)

(...) discursos pronunciados contra España en el Senado norteamericano. El Sr. Call estuvo leyendo, en apoyo de su tesis, un capítulo de horrores atribuidos a España (...) redactado por la junta insurrecta de Nueva York. Mr Morgan dijo luego que según un historiador veraz y fidedigno [cursiva en original], en la guerra de los diez años las fuerzas españolas dieron muerte a 43.600 prisioneros. (...) el historiador no era otro que José Martí, el cabecilla insurrecto y célebre propagandista del filibusterismo. Cuando se apela a esas armas es natural que todas las conciencias honradas se subleven contra procedimientos que necesitan recurrir a la falsedad y a la mentira para buscar pretexto de codicias y malas pasiones (Faro, 13 de marzo de 1896).

En el Consejo se habló extensamente del procedimiento canallesco, propio de gentes sin honor, empleado por los yankees para penetrar en un puerto nuestro, y que fue como ya he telegrafiado, el de izar en sus barcos la bandera española (Faro, 23 de mayo de 1898).

La prensa española que en un primer momento había aplaudido la posición no intervencionista de los EEUU terminó por criminalizarlos, haciendo alusión a ellos como mercaderes, aprovechados, cerdos jingoes, canallas, gentes sin honor, falsos, vanidosos, impíos o inhumanos. Una caracterización negativa de

[u]n pueblo nuevo, sin tradición histórica que lo defina; sin raza determinada que lo caracterice; sin religión que lo inflame; orgulloso de su inopinada riqueza, ansioso de engrandecimiento, aguijoneado por la sed de dominio, influido por el demonio de la vanidad que, según leyes de humana naturaleza, acompaña al goce de la opulencia, ambicioso de justificar el programa, para él profético, de su victoria sobre la vieja Europa que, acaso contemplando prematuramente con ensueño de poeta sus ruinas, saluda su omnipotencia futura (Faro, 7 de marzo de 1896).

Tal como se puede apreciar, la imagen que el Faro ofreció del enemigo yankee se construyó como antítesis de la representación del pueblo español y del ideal del héroe patrio.

El 14 de marzo de 1897 el Faro recogió sus impresiones sobre la entrevista que el nuevo Ministro de Estado de EEUU celebró con el corresponsal de The Times en Washington. Entre otras cuestiones Mr. Sherman, a quien el periodista describe como "un carácter poco serio y carecer de criterio despejado y firme y de la diplomacia que el cargo para el que ha sido requiere", se refiere a la situación en Cuba:

Los yankees no quieren guerra ni conflictos de ninguna especie con España. La anexión de la Isla de Cuba a los Estados Unidos, satisfaría sin duda, las aspiraciones y los deseos de muchos, pero no puede ni debe pensarse en ella, pues provocaría segura- 
mente un rompimiento (sic) con España, y, esto solo, seria causa bastante para que se originasen nuevos actos de rebelión en Cuba en pos de los cuales vendrían quizás mayores y más graves complicaciones.

Yo, he sido y seré, sin que tenga por qué negarlo, amigo personal de los rebeldes que pelean contra España defendiendo la ambicionada independencia de Cuba; pero, desde el momento en que se me llama para ocupar el puesto oficial en que me hallo, todos los personalismos desaparecen y no queda en mi otro deseo que el de cumplir estricta y honradamente mis deberes, uno de los cuales, acaso el primero de todos, es atender a la fiel observación de lo que establece el derecho internacional, y secundar, por cuantos medios estén a mi alcance, la política del presidente Mac Kinley.

Esta respuesta simboliza, de algún modo, el papel que EEUU desarrolló en la contienda cubana, siempre debatiéndose entre su deber con España y sus intereses estratégicos en el Caribe español. Un doble juego, potenciado por la intervención de la prensa de este país (Wilkerson, 1932; Pratt, 1934), que no tardó en ser advertido por los rotativos gallegos.

No es la primera vez que en las columnas del Faro hemos expuesto nuestra firme creencia de que la campaña de Cuba es más que una lucha intestinal una guerra internacional de nuestro pueblo con el pueblo yankee, que de un modo embozado pero claro $\mathrm{y}$ evidente es quien dirige y sostiene el horrible y prolongado combate que en la manigua se desarrolla (Faro, 4 de octubre de 1895).

Incluso en el período de neutralidad de los EEUU, diversas informaciones recogidas por la prensa permiten establecer hilos de conexión con los independentistas cubanos como la expresa simpatía de Mr. Sherman por los insurgentes, la ubicación del Comité de filibusterismo en Nueva York o el reclutamiento de voluntarios estadounidenses para abanderar la causa independentista cubana (Auxier, 1939).

A pesar de las críticas a la actuación de la prensa estadounidense y la publicación con reservas (advirtiendo de la poca fiabilidad de la fuente) de cualquier noticia que proviniese de ésta, en marzo de 1896 el Faro se refiere al hecho de que, en un momento de aparente neutralidad de los EEUU, todos los periódicos norteamericanos

(...) abogan por la previsión de un nuevo conflicto, y aconsejan al gobierno que robusteciendo, por cuantos medios se encuentren a su alcance, la acción militar en Cuba, no de lugar a que las Cámaras de los Estados Unidos vuelvan a tratar sobre el ya debatido asunto del reconocimiento de la beligerancia (Faro, 13 de marzo de 1896).

En lo que se respecta a su potencia naval los EEUU, siguiendo la doctrina Mahan, invirtieron en la construcción de una gran flota que respaldase cualquier intento de expansión ultramarina. Una política a la que se destinó una inversión seis veces mayor que la prevista para la flota española, y que permitió reactivar la industria naval convirtiéndola en una de las más competitivas del mundo (Solar, 1998).

Pese a la indiscutible potencia de la flota estadounidense desplegada en el Caribe español, según el Faro (23 de mayo de 1898) una "fuerza brutal de unas escuadras inmensamente mayores en número a la que la nación enemiga le opone", los rota- 
tivos analizados se prodigaron en la supuesta falta de preparación de los marinos yankees.

Dicen de Nueva York que, persuadido el gobierno yankee de la ineptitud de sus marinos y temiendo quizás que estos, no obstante la superioridad numérica de sus barcos, puedan ser batidos y derrotados por la escuadra del almirante Cervera, ha dispuesto que salgan en busca de ésta 60 buques formando tres escuadras, al mando de cada una, respectivamente, de los almirantes Sanpson, Schely y Wolson (Faro, 23 de mayo de 1898).

Un error del que también eran partícipes los políticos quienes, como Emilio Castelar, defendían que la ignorancia naval del ejército estadounidense lo abocaría al fracaso aún con una flota rápida y poderosa.

Todo el mundo sabe lo mal dirigidas que están las escuadras yankees; todo el mundo sabe la composición abigarradísima de sus tripulaciones, que cuentan desde portugueses hasta chinos; todo el mundo sabe la díficultad en sus levas y lo complicado de instrucciones dictadas muchas veces a marinos llegados de luengas tierras, como los antiguos ejércitos del Papa; cebadísimos por el deseo de la merced y el lucro; con escasas condiciones militares (en Solar, 1998: 254).

Esta inferioridad de la flota yankee fue construida en la prensa gallega por medio de la confrontación dialéctica con la armada española: la habilidad de los marinos patrios "para despistar a la escuadra yankee", personificada en el contralmirante Cervera, versus la escasa destreza y capacidad de reacción de los estadounidenses, representados por el almirante Sampson; la pericia naval española frente a las estrategias canallas y el juego sucio yankee; el papel legítimo de la Corona española contra los espurios intereses yankees, etc.

En definitiva, unas representaciones vehiculadas por las principales cabeceras gallegas del momento, que contribuyeron a la reafirmación de la identidad española y de los valores asociados a la patria.

\section{A modo de conclusión}

Durante la Guerra de Cuba la prensa gallega alimentó las ilusiones de la opinión pública con imágenes míticas del imperio español y de la valentía de su ejército, enriquecidas con elementos legendarios del pueblo gallego y su carácter, en contraposición del enemigo (el mambís filibustero o el impío yankee). Unas representaciones que, si bien en su origen contaban con un núcleo de verdad, en el momento del conflicto bélico distaban bastante de la realidad.

Este papel desempeñado por los rotativos gallegos fue similar al de la prensa española en general y al de otros escenarios de carácter local, como señalan diversos autores (Armero, 1998; Arrollo, 1988; López García, 2001 o Ruiz Acosta, 2001, entre otros). 
No obstante, en ocasiones el Faro y $L a$ Voz se desmarcaron de la línea imperante en las cabeceras nacionales $-\mathrm{O}$ en las madrileñas como referentes patrios- para criticar la falta de atención o la excesiva politización en el tratamiento de un suceso determinado. Crítica que se hizo eco en uno u otro rotativo (Faro o $\mathrm{La} \mathrm{Voz}$ ) en función del color político de la actuación reprobada.

Debido a que ambos periódicos recibían información de la contienda vía Madrid, algunos de estos reproches recogidos en editoriales y crónicas entraron en contradicción con informaciones de carácter noticiosos del mismo ejemplar e, inclusive, de la misma página.

Por otra parte, las cabeceras gallegas se adelantaron a la prensa nacional en la ruptura del clima de optimismo generado con la narración de continuas hazañas bélicas del ejército español.

La proximidad de estos rotativos a los puertos de A Coruña y Vigo, cuya vinculación queda patente en la inclusión de una sección fija relativa al tráfico portuario ("Movimiento del puerto"), los convierte en testigos del desembarco de tropas provenientes de Cuba.

Este retorno de excombatientes y heridos de guerra fue narrado con dureza en las páginas del Faro y de $\mathrm{La} \mathrm{Voz}$ en un momento en el que el discurso de la prensa española $-y$ el suyo propio- mantenía el espejismo de superioridad del imperio español y de una inminente victoria.

En definitiva, resulta reseñable la denuncia de los periódicos gallegos al papel propagandístico de la prensa estadounidense, especialmente desde la perspectiva de su propia cobertura de la insurrección y guerra cubana. Una cobertura más próxima a los intereses del Imperio que a la realidad del contexto bélico.

\section{Referencias bibliográficas}

ALONSO VALDÉS, C. (2007). La inmigración china: Ejército Libertador de Cuba (1895-1898). Extraído el 20 de mayo de 2011 de http://embacuba.cubaminrex.cu/ Default.aspx?tabid $=5598$

ÁLVAREZ, J.T. (1996). "Opinión pública y propaganda bélica al inicio de la contienda" En: De DIEGO, E. (dir.) (1996). 1895: La Guerra en Cuba y la España de la Restauración. Madrid: Editorial Complutense. pp. 247-263.

ARMERO, A. (1998). Fragmentos del 98: Prensa e información en el año del desastre. Madrid: Comunidad Autónoma de Madrid.

AROLLO CABELLO, M. (1998). "La prensa murciana en el desastre del 98". En: Historia y Comunicación Social, $\mathrm{n}^{\mathrm{o}}$ 3, Madrid: Universidad Complutense de Madrid. p. $15-25$.

AUXIER, G.W. (1939). "The propaganda activities of the Cuban Junta in precipitating the Spanish-American War, 1895-1898". En The Hispanic American Historical Review, vol. 19, no 3, Durham: Duke University Press. pp. 286-305.

BARREIRO FERNÁNDEZ, X. R. (1997). "Galicia ante o 98". En: Actas do Congreso de Galicia nos tempos do 98. Santiago de Compostela: Xunta de Galicia. p. 5-28.

CAMPBELL, W.J. (2001). Yellow Journalism: Puncturing the Myths, Defining the Legacies. Westport: Greenwood Publishing Group. 
COMPANYS MONLUS, J. (1998). La prensa amarilla norteamericana en 1898. Madrid: Sílex.

DE DIEGO, E. (dir.) (1996). 1895: La Guerra en Cuba y la España de la Restauración. Madrid: Editorial Complutense.

DE QUESADA, G. (1868). Los chinos y la independencia de Cuba. La Habana: Heraldo.

GARCÍA MORA, L. M. (2001). "La fuerza de la palabra. El autonomismo en Cuba en el último tercio del siglo XIX". Extraído el 20 de marzo de 2010 de http://reccma.es/libros-pdf/luis-miguel-garcia-mora-01.pdf

GONZÁLEZ-RIPOLL, M.D.; GARCIA, L.M. (1997). El Caribe en la época de la independencia y las nacionalidades. Morelia: Univ. Michoacana S. Nicolás de Hidalgo.

GUERRA, R. (1971). Manual de historia de Cuba. La Habana: Ed. de Ciencias Sociales. HERNÁNDEZ SANDIOCA, E. (2002). "La historiografía más reciente sobre el 98”. En: Iberoamericana. América Latina-España-Portugal. Ensayos sobre letras, historia y sociedad, vol. 5. Berlin-Frankfurt: Instituto Ibero-Americano de Berlín, Instituto de Estudios Iberoamericanos de Hamburgo y Editorial Iberoamericana. p. 213-222.

HILTON, S. (2010). "Estudio introductorio. Relaciones históricas hispano-estadounidenses: visiones del siglo XX en clave cultural". En: Revista Complutense de Historia de América, vol. 36. Madrid: Universidad Complutense de Madrid. p. 13-35.

IGLESIAS AMORÍN, A. (2008). Imagen y repercusiones de la Guerra de Cuba en Galicia (1895-1898). Santiago: Universidade de Santiago de Compostela.

LEGUINECHE, M. (1998). Yo pondré la Guerra. Cuba 1898, la primera guerra que se inventó la prensa. Madrid: Aguilar.

LÓPEZ GARCÍA, G. (2001). "La primera Guerra mediática: la prensa en la Guerra de Cuba”. En CALVO PÉREZ, J. (ed.) (2001). Contacto interlingüistico e intercultural en el mundo hispano. Valencia: Universidad de Valencia. Vol. II, p. 803-811.

MAESTRO, J. (1989). "El hundimiento del 'Maine' y el conflicto hispanoamericano en Hufvudstadsbladet, el diario finlandés de mayor tirada de la época”. En: Historia y Comunicación Social, $\mathrm{n}^{\mathrm{o}}$ 3, Madrid: Universidad Complutense de Madrid. p. 95-96.

NARANJO OROVIO, C. (coord.) (2009). Historia de Cuba. Madrid: Doce Calles-CSIC.

PASCUAL, P. (1997). "La prensa de España, Cuba, Puerto Rico y Filipinas y las Guerras de Independencia (1868-1898)". En: RUBIO CORDÓN, J.L. (Coord.) (1997) VI Encuentro de Latinoamericanistas Españoles. Extraído el 20 de mayo de 2010 de http://www.ucm.es/info/cecal/encuentr/intro.htm

PIZARROSO QUINTERO, A. (1998). "Guerra, cine e historia. La guerra de 1898 en el cine”. En: Historia y Comunicación Social, n 3, Madrid: Universidad Complutense de Madrid. p. 143-162.

PRATT, J.W. (1934).“American Business and the Spanish-American War”. En The Hispanic American Historical Review, vol. 14, n 2, Durham: Duke University Press. p. 163-201.

RUIZ ACOSTA, M.J. (1996). Sevilla e Hispanoamérica: Prensa y opinión pública tras el Desastre de 1898. Sevilla: Escuela de Estudios Hispano-Americanos.

RUIZ ACOSTA, M.J. (2001). "Entre la estima y el reproche. La visión de la prensa sevillana acerca de las relaciones entre España e Hispanoamérica (1898 -1903)". En: Anuario de Estudios Americanos, vol. 58, n 1, Sevilla: Escuela de Estudios HispanoAmericanos de Sevilla (CSIC), p. 209-226. 
SANCHEZ PUPO, M. (1998). La prensa norteamericana llama a la guerra. 1898. La Habana: Editorial Ciencias Sociales.

SANTAMARÍA, A.; NARANJO, C. (1999). "El 98 en América. Últimos resultados y tendencias recientes de la investigación”. En: Revista de Indias, vol. 59, n. 215. Madrid: Instituto de Historia del CSIC. p. 203-274. Extraída el 10 de febrero de 2010 de: http://dx.doi.org/10.3989/revindias.1999.i215.745

SANTOS, F. (1998). La prensa y la Guerra de Cuba. Bilbao: Asociación Julián Zugazagoitia.

SEOANE, M.C.; SÁIZ, M.D. (1996). Historia del periodismo en España. El siglo XX: 1898-1936. Madrid: Alianza Universidad.

SEVILLA SOLER, R. (1998). "España y Estados Unidos: 1898, impresiones del derrotado". En: Revista de Occidente, nos 202-203. Madrid: Fundación José Ortega y Gasset. p. 278-293.

SOLAR, D. (1998). "Una Guerra por encima de las posibilidades españolas". En Historia y Comunicación Social, $\mathrm{n}^{\mathrm{o}}$ 3, Madrid: Universidad Complutense de Madrid. p. 239-259.

THOMAS, H. (1973). Cuba: la lucha por la libertad, 1762-1970. Barcelona: Grijalbo. Vol. 1.

WILKERSON, M. M. (1932). Public Opinion and the Spanish-American War: A Study in War Propaganda. Baton Rouge: Louisiana State University Press.

\section{Notas}

1 Faro de Vigo, ejemplares consultados $\mathrm{n}^{\mathrm{o}} / \mathrm{mes}$.

\begin{tabular}{|c|c|c|c|c|c|c|c|c|c|c|c|c|}
\hline & Ener & Feb. & Marz & Abril & May & Junio & Julio & Agst. & Sep. & Oct. & Nov. & Dic. \\
\hline 1895 & 25 & 23 & 27 & 24 & 26 & 25 & 25 & 26 & 25 & 27 & 26 & 25 \\
\hline 1896 & 23 & 24 & 24 & 25 & 26 & 25 & 27 & 26 & 25 & 27 & 25 & 26 \\
\hline 1897 & 26 & 23 & 24 & 25 & 25 & 23 & 27 & 27 & 25 & 28 & 25 & 26 \\
\hline 1898 & 25 & 22 & 27 & 27 & 31 & 30 & 30 & 31 & 25 & 26 & 25 & 31 \\
\hline
\end{tabular}

2 En septiembre de 1898, el Faro criticaba la exclusión del puerto de Vigo de los puntos de desembarque para la repatriación de las fuerzas desplazadas en Cuba y Puerto Rico (Faro, 22 de septiembre de 1898).

3 Circunstancia que resulta llamativa si se atiende al hecho de que a inicios del mes de abril de 1895 Beranger, por entonces Ministro de Marina, anunciaba la construcción de ochenta cañoneros en EEUU con destino Cuba (Faro, 6 y 7 de abril de 1895).

\section{La autora}

Teresa Piñeiro-Otero es Doctora por la Universidad de Vigo y Licenciada en Publicidad y Relaciones Públicas por la misma universidad. Ha centrado su ámbito de investigación en las representaciones de diversos grupos sociales en los medios de comunicación y la publicidad, con especial atención a la estereotipia de género. En la actualidad es docente en la Facultad de Ciencias de la Comunicación de la Universidade da Coruña, donde imparte la asignatura de Teoría de la Comunicación. 